\title{
COMUNICAÇÃO E MÍDIA: UMA QUESTÃO SOCIAL NO SERVIÇO DA SAÚDE
}

\author{
COMUNICACIÓN Y MEDIOS: UNA CUESTIÓN SOCIAL EN EL \\ SERVICIO DE LA SALUD
}

\section{COMMUNICATION AND MEDIA: A SOCIAL QUESTION IN THE HEALTH SERVICE}

\author{
José Anderson SANTOS CRUZ 1 \\ Lucas Justiniano BERMEJO ${ }^{2}$ \\ Arielly KIZZY CUNHA ${ }^{3}$
}

RESUMO: O presente artigo tem por objetivo analisar o processo comunicacional entre as Unidades Básicas de Saúde e agentes de Saúde Pública do Município de Bauru-SP. Como metodologia, utilizamos a observação assistemática, a aplicação de questionários de caráter descritivo-exploratório e a revisão bibliográfica e documental. Como resultado, a pesquisa apresentou a necessidade de melhoria nas estratégias informacionais com seus usuários, além de uma valoração no papel do serviço social como mediador e promotor das campanhas de saúde.

PALAVRAS-CHAVE: Comunicação. Serviço social. Saúde.

RESUMEN: Este artículo pretende analizar el proceso de comunicación entre las unidades básicas de salud y funcionarios de salud pública en el ciudad de Bauru-SP como metodología, tomamos nota de los cuestionarios de carácter descriptivo exploratorio no sistemáticos, aplicando y bibliográfico y documental. Como resultado, la encuesta mostró la necesidad de mejora en las estrategias informativas con los usuarios, además de una valoración en el rol de servicio social como mediador y promotor de campañas de salud.

PALABRAS-CLAVE: Comunicación. Servicio social. Salud.

ABSTRACT: This article aims to analyze the communicational process between the basic health units and Public health officials in the city of Bauru-SP as a methodology, we note unsystematic, applying descriptive-exploratory character questionnaires and bibliographical and documentary. As a result, the survey showed the need for

${ }^{1}$ Universidade Estadual Paulista (Unesp), Araraquara - SP - Brasil. Doutorando em Educação Escolar, Faculdade de Ciências e Letras de Araraquara. Bolsista CAPES. E-mail: joseandersonsantoscruz@gmail.com

${ }^{2}$ Faculdade Anhanguera de Bauru, Bauru - SP - Brasil. Aluno Especial do PPG em Educação Escolar, Faculdade de Ciências e Letras de Araraquara. Coordenador dos curros de graduação - Biomedicina e Biologia. E-mail: lucasjbermejo@hotmail.com

${ }^{3}$ Universidade Estadual Paulista (Unesp), Bauru - SP - Brasil. Doutoranda pelo PPG em Mídias e Tecnologias, FAAC/Unesp. Bolsista CAPES. E-mail: ariellykizzy@yahoo.com.br 
improvement in the informational strategies with your users, in addition to a valuation in the role of social service as a mediator and promoter of health campaigns.

KEYWORDS: Communication. Social service. Health.

\section{Introdução}

Como fator agravante desse quadro, temos a deficiência no atendimento que é causada pela falta de investimentos e o aumento constante da demanda. Assim, os programas de prevenção ganham importância para manter o bem-estar da população.

Vasconcelos (2011) comenta que enquanto não admitirmos a gravidade desse quadro, dificilmente estaremos contribuindo com as entidades da categoria, com as unidades formadoras e, principalmente, os assistentes sociais. Com esta percepção, podemos comentar que é necessária e de suma importância o papel do serviço social na orientação da população usuária e, que estes devem proporcionar à população usuária orientações na prevenção de doenças. Com isso, o município tem somente a ganhar já que a prevenção é o melhor caminho para diminuir ou até mesmo erradicar doenças.

A partir desse ponto, pode-se afirmar que uma boa comunicação é essencial para manter a eficiência do serviço de Saúde Pública, e, garantir a toda a população as informações necessárias para a prevenção de enfermidades. Além disso, também cabe a comunicação, manter o diálogo entre as Unidades Básicas de Saúde (UBS), os médicos, o serviço social garantindo integração entre todos os envolvidos. Sales e Ruiz (2009) afirmam que em tempos passados, a comunicação era entendida como o objeto comum: uma comunicação ou um comunicado. Também foi compreendida como meios físicos de transporte como as vias de comunicação e os meios tecnológicos de transmissão de informação.

No entanto, pressupõe-se a possibilidade de construir um objeto, portanto, uma teorização da intervenção profissional que, a partir dos conhecimentos no serviço social, é relevante a sua colocação na prática. A produção de conhecimento se dá através de análises, observações, pesquisas e estudos que, a priori, surgem a partir das necessidades reais dentro de um contexto social específico, no caso, na saúde.

Nesse contexto, é vital conhecer a importância do assistente social, que assume o papel de transmissor das comunicações na área, enfocando a realidade e promovendo as campanhas de prevenção através de informativos impressos, palestras e orientações. $\mathrm{O}$ que também mostra a importância da participação de todos os envolvidos que 
colaboram com a atuação do assistente social. Embora as medidas em campanhas de informação sejam verticais, ou seja, centradas e promovidas a partir da Secretaria de Saúde, os agentes diretamente envolvidos (as UBS, a população usuária e os profissionais de saúde) são a força motriz do processo comunicacional, e, exatamente por isso, as medidas e campanhas devem estar em constante diálogo para que atinjam resultados efetivos.

Assim, o presente trabalho busca, através da observação sistemática, da aplicação de questionários e de revisão bibliográfica e documental, analisar o processo comunicacional que envolve as agências (UBS e Secretaria da Saúde) e os agentes (assistente social e demais profissionais da área) da Saúde Pública do município de Bauru, Estado de São Paulo. E, a partir dessa analise, propor medidas que possam garantir uma maior eficácia na comunicação interna e externa.

\section{Comunicação e seus derivados}

\section{Conceitos da comunicação}

O termo comunicação vem do latim communicatio, do qual distinguimos três elementos: uma raiz munis, que significa "estar encarregado de", que acrescido do prefixo co, o qual expressa simultaneidade, reunião, temos a ideia de uma " atividade realizada conjuntamente", completada pela terminação tio, que por sua vez reforça a ideia de atividade. E, efetivamente, foi este primeiro significado no vocabulário religioso aonde o termo aparece pela primeira vez (HOHLFELDT; MARTINO; FRANÇA, 2007, p.12-13).

O termo comunicação, quando ausente de definição, pode levar a diversas interpretações. Assim, faz-se necessário interpor uma definição precisa que caracterize a sua relevância para o tema em questão.

Durante muito tempo, era quase consensual a ideia de que comunicação era somente a emissão de uma mensagem para um receptor, mas, pouco era destacada a necessidade de se obter o feedback do receptor. Cruz (2011) cita Dimbleby e Burton que a comunicação é a maneira de persuadir os outros como agem ou pensam. Mas a comunicação passa a ser um canal de transformações, necessidades, e a união de meios, 
mediação, canal, emissor, receptor. A necessidade do feedback do receptor é fundamental para responder se houve comunicação ou não.

Comunicação em saúde diz respeito ao estudo e utilização de estratégias de comunicação para informar e para influenciar as decisões dos indivíduos e das comunidades no sentido de promoverem a sua saúde segundo Teixeira (2000). O conceito apresentado pelo autor traduz de forma ampla para englobar todas as áreas nas quais a comunicação é relevante em saúde. A comunicação não é apenas para promover a saúde, embora esta seja a área estrategicamente mais importante. Porém, a comunicação em saúde inclui mensagens que podem ter finalidades muito diferentes.

Esta polissemia, com relação à definição do que se compreende por comunicação em saúde para prevenção e promoção, impacta a possibilidade de se visualizar modelo único de comunicação nas práticas de intervenção, na medida em que, produz um emaranhado discursivo de estratégias e práticas chamadas de "comunicação para mobilização social", "comunicação e marketing social em saúde", "comunicação $e$ advocacy midiática", "comunicação para mudança social", "comunicação e educação em saúde", entre outros [...] (MONTORO, 2008, s/p).

As mais variadas interpretações, signos, significantes e significados, quando falamos das mensagens transmitidas para os públicos através dos meios de informação e pelos indivíduos envolvidos nesse processo. Por conseguinte, parte de um processo produtivo que visa inserir, gerar e consumir ideias para diversos objetivos e públicos, o que pressupõe a relevância da comunicação no serviço social, que busca garantir uma propagação das necessidades no aspecto da saúde.

A comunicação trata das questões e formas de como atingir o receptor e promove estratégias para garantir a eficácia e eficiência das informações transmitidas. Para tanto, se utiliza da comunicação verbal, comunicação oral, comunicação comunitária, comunicação dirigida, mídia impressa e televisiva. O exercício profissional da comunicação, na maioria das vezes, irá encontrar o assistente social na qualidade de cliente, em outras ocasiões, como membro da equipe na execução de campanhas informativas e educativas. Nos dois casos, sucessivas mudanças no contexto social têm levado à necessidade de ampliar mutuamente o conhecimento [...] (SALES; RUIZ, 2009, p. 144).

A dissociação entre planejamento de saúde e de comunicação é particularmente evidente em alguns extratos do discurso dos gestores: 
O planejamento logístico das ações de saúde antecede o planejamento de ações de comunicação"; "O planejamento de comunicação não faz parte do planejamento de ações de saúde dos gestores técnicos (MONTORO, 2008, s/p).

A estratégia de comunicação pressupõe a necessidade de comunicar-se com o público, sendo assim, o serviço social é um segmento que necessita de ações estratégicas de comunicação para atingir seus usuários de forma direta, e, neste caso, o serviço social atuante na saúde.

\begin{abstract}
A Comunicação em Saúde surge não só como uma estratégia para prover indivíduos e coletividade de informações, pois reconhece-se que a informação não é suficiente para favorecer mudanças, mas é uma chave, dentro do processo educativo, para compartilhar conhecimentos e práticas que podem contribuir para a conquista de melhores condições de vida. Reconhece-se que a informação de qualidade, difundida no momento oportuno, com utilização de uma linguagem clara e objetiva, é um poderoso instrumento de promoção da saúde. O processo de comunicação deve ser ético, transparente, atento aos valores, opiniões, tradições, culturas e crenças das comunidades, respeitando e considerando e reconhecendo as diferenças, baseando-se na apresentação e avaliação de informações educativas, interessantes, atrativas e compreensíveis (MOISÉS, 2011, $\mathrm{s} / \mathrm{p})$.
\end{abstract}

Compreender os conceitos da comunicação contribui para a gestão estratégica da comunicação, e, facilita o processo de integração e disseminação da informação necessária aos receptores por canais diversos, que, além de decifrar os códigos da comunicação de forma ágil, interpõe o feedback rapidamente.

\title{
Comunicação de massa
}

A comunicação de massa busca atingir um grande número de indivíduos, assim, não há como falar em comunicação de massa sem adentrar os conceitos de cultura de massa.

O Estado se utiliza da comunicação de massa para mostrar, apresentar, divulgar as campanhas de serviço social, saúde, educação, entre outros. Desta forma consegue chegar próximo a toda a sociedade. 
A comunicação de massa é a comunicação feita de forma industrial, ou seja, em série para atingir um grande número de indivíduos, a sociedade de massa. Numa visão apocalíptica, ela é uma conversão da cultura em mercadoria, utilizada pelas classes dominantes de forma vertical para homogeneizar as massas. (JORNAL DEBATES, 2011, $\mathrm{s} / \mathrm{p})$.

Canclini (2006), por sua vez, afirma que se trata da montagem de um quebracabeça: entender como as forças hegemônicas vêm conseguindo se situar nos cenários estratégicos da economia, da política e da comunicação (apud CRUZ, 2011). O autor apresenta como as forças contribuem nas questões acerca da comunicação, e que, além de consumidores somos cidadãos que buscam utilizar os serviços do Estado.

\begin{abstract}
Observa-se que há concepções diferentes sobre o papel e fundamento mesmo da comunicação em saúde, que vai desde o paradigma clássico da comunicação para o desenvolvimento, que se baseia na construção de um modelo de comportamento saudável transposto e imposto de um país desenvolvido para um subdesenvolvido; passando pela comunicação para promoção da saúde em que se enfatiza o repasse de informação e a promoção de conhecimentos, como valiosos instrumentos para participação e as mudanças dos estilos de vida nas comunidades, chegando à comunicação estratégica em que a comunicação para saúde só pode ser atingida pelo estabelecimento de uma interdependência sistêmica da comunicação com a tecnologia da informação (MONTORO, 2008, s/p).
\end{abstract}

Wolf (2009), comenta que todo consumidor de mídia, ou seja, as comunicações de massa é uma realidade cada vez mais próxima dos públicos. Essa pequena apresentação, nos aponta os mais variados caminhos a serem percorridos na formação dos profissionais. Portanto, produzindo uma educação no âmbito social favorecendo mudanças de comportamentos e hábitos.

\title{
Comunicação dirigida
}

As Novas Tecnologias da Comunicação e da Informação (NTCI's) fornecem ao homem cada dia mais a possibilidade de acesso a informação. Em consequência, o processo de globalização se torna cada vez mais veloz. Com esse novo cenário social, as empresas e organizações adaptaram seu modo de se comunicar aos utilizados pelo seu público-alvo, assim, as ações passaram a ser tomadas de maneira mais eficaz. Com isso, 
surge cada vez mais a necessidade de uma comunicação dirigida que consiga segmentar os públicos de maneira precisa.

Segundo Kunsh (1997) o conceito da comunicação dirigida destina-se a públicos específicos, pré-determinados, e, consequentemente, mais conhecidos pelos idealizadores das diferentes estratégias de aproximação possíveis. Para Andrade (1965,) a comunicação dirigida é um processo que tem por finalidade transmitir ou conduzir informações para estabelecer comunicação limitada, orientada e frequente com determinado número de pessoas com características homogêneas.

Com a Revolução industrial, inicia-se a "segunda onda" ou "sociedade industrial", onde a "fábrica" passa a ser a unidade produtora de recursos econômicos e principal fonte de empregos. No entanto, o avanço da tecnologia, da informática, da robótica e da telecomunicação apresenta um quadro novo: o trabalho físico e intelectual do homem é substituído pelas inovações técnicas, proporcionando o aparecimento da "terceira onda ou sociedade da informação" (FERREIRA, 1997, s/p).

Na Comunicação Dirigida não há massificação, mas, os jornais, as revistas, o rádio e a televisão - principais meios de comunicação de massa da "segunda onda" estão cada vez mais se especializando e se utilizando dela para atingirem determinados públicos ou parte de seus públicos. Com isso, a comunicação dirigida cabe a elaboração de uma mensagem eficiente, eficaz e apta para produzir os efeitos e resultados no público receptor.

\section{Comunicação midiática do Governo Federal}

O Estado utiliza-se da comunicação de massa para divulgar campanhas acerca das questões da saúde e promovendo a informação para os usuários que buscam os serviços em UBS espalhados pelo país.

No âmbito federal, as deficiências na coordenação temporal e logística acarretam frequentes atrasos na distribuição, para estados e municípios, de materiais de campanha e impressos produzidos pelo governo federal, o que acaba por inviabilizar sua utilização. Como resultado, no planejamento anual, vários gestores estaduais $\mathrm{e}$ municipais não consideram a utilização do material de campanha produzido pela esfera federal, optando pela produção de materiais regionais, tendo, como consequência, a redundante superposição de 
conteúdos e o desperdício de material. Paradoxalmente, estes problemas logísticos surgem também como estímulo e oportunidade para o planejamento de campanhas e materiais regionais e locais (MONTORO,2008, s/p).

Porém é necessário que todos os municípios estejam engajados nas campanhas, para isso, participar da divulgação em suas comunidades pertencentes aos municípios. Em 2011, conforme figura 1, o governo iniciou a campanha na TV aberta com apoio do Ministério da Saúde sobre o combate a AIDS, iniciando antes do carnaval. Estas comunicações oferecem um dialogo de prevenção, alertando a sociedade e a todos os cidadãos que com saúde não se brinca. Mas faz-se necessário ainda uma aproximação maior, um acompanhamento mais familiar e assim o município deve estar atento às necessidades em sua cidade com a população.

Figura 1: Campanha AIDS - Carnaval 2011

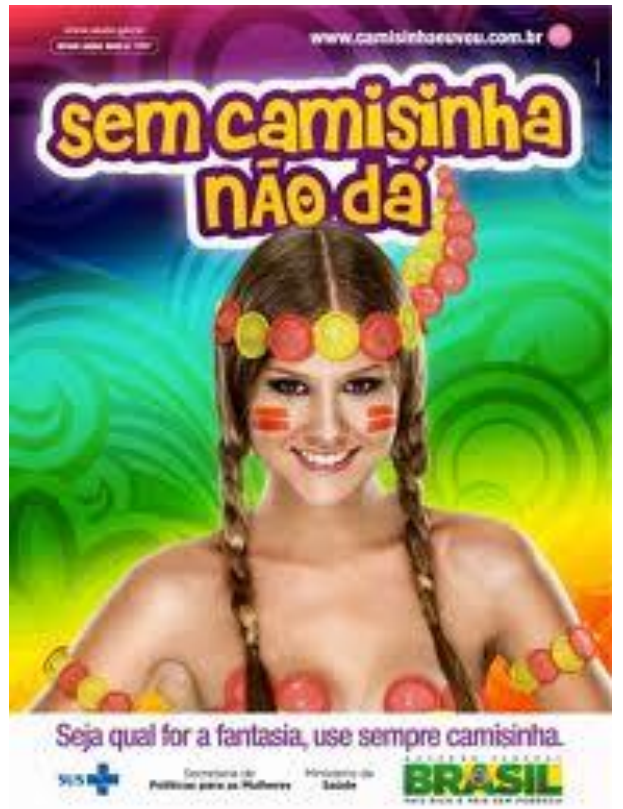

Fonte: bvsms.saude.gov.br

A campanha de carnaval do Ministério da Saúde contra a AIDS, lançada dia 25 de fevereiro de 2011, tem como foco jovens entre $15 \mathrm{e}$ 24 anos. De acordo com o Departamento de DST, AIDS e Hepatites Virais, a campanha vai ter duas fases. Antes da folia, o foco vai ser na importância do uso da camisinha e a sugestão de que cada folião já chegue à festa com seu preservativo no bolso. Depois do período da festa, o objetivo será estimular os foliões que tiveram relação desprotegida a fazer o teste HIV. Período de veiculação: 25/2/2011 a 14/3/2011 (SUS, 2012, s/p). 
As campanhas publicitárias que norteiam a comunicação de massa veiculada com autorização do governo visam levantar e apresentar, através da divulgação com imagens, os cuidados que devemos ter e os riscos que corremos em determinadas situações. Desta forma, o governo se utiliza da comunicação para estimular seus cidadãos a terem medidas preventivas de saúde e evitar situações de risco. Esta é uma questão que cabe ao serviço social, pois, a publicidade midiática dessas campanhas gera um efeito de necessidade para a prestação do serviço pelo governo.

A saúde é um direito do cidadão garantido no Artigo $5^{\circ}$ da Constituição Federal de 1988. Para Jvilsemar (2007), vivemos em uma época de transição de pensamentos, de novos costumes impostos pela globalização capitalista e de pouca valorização pela vida. O pior é a ampliação da falta de humanização e o despreparo profissional por parte de pessoas ligadas a saúde. São elas que estão a lidar com o dom precioso da vida e a preservação da saúde que deveria de ser com qualidade.

\section{O serviço social e suas práticas na saúde}

A designação profissional do serviço social é de desenvolver ações e estratégias para a população de modo geral, pressupondo o contexto das políticas públicas assistenciais com o propósito de solucionar ou diminuir as situações que desfavorecem a sociedade. O serviço social está presente em todas as áreas, seja no setor privado ou público. A fase atual do capitalismo, que se encontra como sistema econômico de quase todos os países do globo, acaba por atenuar e produzir problemas sociais como desemprego, condições precárias de vida, pobreza, falta de acesso a saúde e educação, etc.

A prática do Serviço Social, a partir dos eixos estruturantes: Sistema Único de Assistência Social (SUAS) e o Sistema Único de Saúde (SUS) vêm a mostrar de forma mais ampla e estruturada as organizações e processos envolvidos. A interação entre as três esferas do governo (União, Estado e Município), entendendo e praticando a legislação, incentivando para que a população usuária possa desfrutar dos serviços assistenciais que têm direito.

Além disso, cabe ao Serviço Social: fortalecer a relação entre Estado e sociedade civil; ter compromisso do social; qualificar os recursos humanos envolvidos tendo em 
vista a obtenção de resultados favoráveis para um serviço de qualidade; auto-avaliar a prestação de serviços, conhecer os conceitos do SUAS; e observar que os desafios acompanham o seu desenvolvimento e, para isso, todos precisam contribuir e investir no conhecimento e capacitação.

O profissional do Serviço Social que atua área da saúde possui uma realidade complexa e, ao mesmo tempo, contraditória, pois, se faz necessário criar articulações com seus superiores nas questões relacionadas as políticas públicas,ou seja, romper com práticas burocráticas para desenvolver sua atividade com a maior eficiência possível. Não obstante, conhecer as práticas da saúde é determinante para o profissional agir e conseguir atender a demanda.

Para Rocha, Santos e Pereira (2010), o Serviço Social tem como principal objetivo garantir o acesso e ampliação dos direitos sociais à população frente as mais diversas políticas públicas de saúde, educação, habitação, assistência social, previdência, etc. Buscando ampliar e facilitar o acesso dos usuários aos direitos de cidadão, o que incluí os benefícios e serviços disponíveis na rede de instituições locais, através do diagnóstico social realizado nos atendimentos individuais ou em grupo, bem como, nas visitas domiciliares e nos encaminhamentos interssetoriais. $\mathrm{O}$ assistente social na saúde atua frente a diversos fatores que dificultam a garantia por detrás de seu atendimento, que vão das dificuldades de atendimento gratuito pelo SUS, principalmente, quando se tratam de consultas especializadas, de exames de alto custo, de falta de leitos em hospitais, órteses, próteses, medicações de uso contínuo e dos programas das Secretarias de Saúde Estadual e Municipal.

Portanto, o Serviço Social vincula-se a projetos que favorecem a construção de uma sociedade mais justa, que busque garantir a população um atendimento digno na saúde como forma de garantir seus direitos básicos de cidadão.

Para isso, o profissional dessa área se utiliza de ferramentas e estratégias que permitam atender as demandas a fim de suprir as necessidades dos usuários das Unidades Básicas de Saúde. Haja vista que a saúde é uma questão cultural baseada nos conhecimentos da população e nas práticas profissionais. Assim, a prevenção é um fator distante na maioria dos casos, portanto, o papel do Serviço Social e da equipe multidisciplinar é de promover a prevenção através de palestras, orientações e demais mecanismos que os façam se aproximar da sociedade. 
A cultura, portanto, é aqui entendida como todo processo humano que se constrói na prática social. Além disso, como destaca o artigo 215 da Constituição Federal e o artigo 27 da Declaração dos Direitos Humanos, a cultura é reconhecida como um direito de todos os cidadãos. (PESTANA, 2011, p. 83).

A comunicação de massa oferecida pelo Ministério da Saúde como prevenção às situações de doenças se inserirem neste contexto, pois, a partir de uma adequação dos hábitos culturais dos indivíduos é possível a assimilação de hábitos preventivos, porém, não menos importante é a atuação do SUS para que se ampliem as melhorias relacionadas a saúde dos usuários.

\section{Atenção Básica da Saúde: promoção em saúde e prevenção de doenças}

Entende-se por promoção de saúde as ações que visam levar ao indivíduo melhorias no que se refere a qualidade de vida, expressas pela garantia de alimentação básica, sono correto, habitação adequada e atendimento as necessidades. Tais necessidades são encontradas na pirâmide de Maslow conforme figura 2.

Figura 2: Pirâmide de Maslow

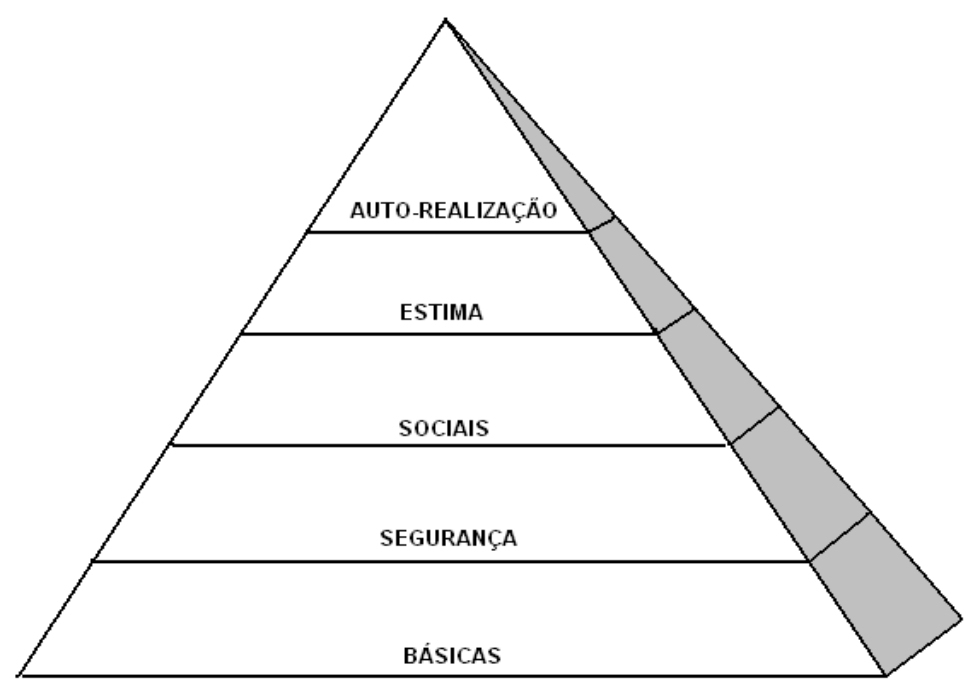

Fonte: Artigonal, 2001

Tais necessidades são a base para que os seres humanos tenham os seus valores e sua dignidade respeitados conforme a Constituição Federal de 1988. Sendo assim, a 
prevenção de situações de risco que possam afligir a saúde do cidadão garante que o Serviço Social participe mais nas questões de divulgação, como nas técnicas de comunicação dirigida e no desenvolvimento de projetos.

\begin{abstract}
As mudanças econômicas, políticas, sociais e culturais, que ocorreram no mundo desde o século XIX e que se intensificaram no século passado, produziram alterações significativas para a vida em sociedade. Ao mesmo tempo, tem-se a criação de tecnologias cada vez mais precisas e sofisticadas em todas as atividades humanas e o aumento dos desafios e dos impasses colocados ao viver. A saúde, sendo uma esfera da vida de homens e mulheres em toda sua diversidade e singularidade, não permaneceu fora do desenrolar das mudanças da sociedade nesse período (PNPS, 2012, s/p).
\end{abstract}

A promoção de saúde além de inserir a prevenção e garantir de forma mais eficaz o direito constitucional à saúde, visa também melhorias em questões relacionadas à superlotação e demora nos agendamentos de consultas. As estratégias utilizadas na promoção da saúde podem ser diversas e em vários locais, podendo ser aplicada dentro de cada UBS, bem como, através do Programa de Médico de Família.

\begin{abstract}
A promoção da saúde, como uma das estratégias de produção de saúde, ou seja, como um modo de pensar e de operar articulado às demais políticas e tecnologias desenvolvidas no sistema de saúde brasileiro, contribui na construção de ações que possibilitam responder às necessidades sociais em saúde (PNPS,2012, s/p).
\end{abstract}

Segundo Buss (2010), para atingir um estado de completo bem-estar físico, mental e social, os indivíduos e grupos devem saber identificar aspirações, satisfazer necessidades e modificar favoravelmente o ambiente natural, político e social. A saúde é, portanto, um conceito positivo, que enfatiza os recursos sociais e pessoais, bem como as capacidades físicas. Assim, não é responsabilidade exclusiva do setor saúde e vai além de um estilo de vida saudável, na direção de um bem-estar global.

E, acerca das questões da promoção de saúde, se esperam que as políticas públicas possam favorecer a sociedade, melhorando as condições de vida. $\mathrm{O}$ autor ainda continua relatando que as necessidades para tais melhorias estão asseguradas na construção de mudanças necessárias na economia e nos padrões econômicos.

\title{
Comunicação em Promoção da Saúde - UBS
}


De acordo com Andrade (1965), a comunicação dirigida é um processo que tem por finalidade transmitir ou conduzir informações para estabelecer comunicação limitada, orientada e frequente com determinado número de pessoas homogêneas e identificada. Sendo assim, as UBS direcionam a comunicação para seus usuários e para a comunidade local, contribuindo para uma prevenção e o conhecimento das necessidades.

Segundo Kunsh (1997), o conceito de comunicação dirigida destina-se a públicos específicos, pré-determinados, e, consequentemente, mais conhecidos pelos idealizadores das diferentes estratégias de aproximação. Conhecer a população usuária produz uma comunicação eficaz e eficiente, tornando-se direta e com resultados satisfatórios. Portanto, a comunicação dirigida quando obtém sucesso corrobora positivamente para a disseminação cultural da prevenção, o que, além de promover melhores cuidados com a saúde pessoal, é capaz de melhorar o controle de enfermidades que atinjam a coletividade, bem como, uma conscientização contra a exposição a situações de risco.

Além das atividades já designadas aos assistentes sociais, também existem as campanhas promovidas pelo Governo Federal, veiculadas pelo Ministério da Saúde. Essas campanhas, quando designadas para as UBS, são assimiladas e adaptadas a cada realidade, e, a partir daí são promovidas ação in loco para atender com mais eficácia as necessidades locais. Essas campanhas federais são, em grande maioria, sazonais, ou seja, são designadas para um período específico em que se concentram a maior incidência de casos ou de fatores agravantes. Destacamos principalmente:

- Vacinação contra a gripe, destinada a idosos, crianças e gestantes que ocorre de abril a junho;

- Vacinação contra a poliomielite, destinada ao público infantil (até cinco anos);

- Campanha contra a hipertensão e diabetes, destinadas a usuários que possuem pressão arterial acima dos índices saudáveis;

- Campanha para gestantes;

- Campanha para a prevenção de Doenças Sexualmente Transmissíveis (DST’s), etc. 
Neste sentido, considerando as necessidades dos usuários, a sala de espera tem o intuito de garantir um cuidado humanizado, efetivando a aproximação cada vez maior entre a comunidade e os serviços de saúde. É por meio da sala de espera os profissionais da área da saúde tem a oportunidade de estar desenvolvendo atividades que extrapolam o cuidado, como a educação em saúde, auxiliando na prevenção de doenças e na promoção da saúde [...] (RODRIGUES et al, 2009, p.101).

Porém, observa-se a necessidade de melhorias na comunicação dirigida in loco, ou seja, busca-se que a informação deve ser direta e conjunta ao atendimento ao usuário. Por exemplo, podemos citar as salas de espera onde os aguardam o atendimento, neste espaço, é possível aproveitar o momento para palestras mais direcionadas com a necessidade da comunicação dirigida, e isso pode ser realizado tento por um agente comunitário quanto pelo profissional do serviço social. Sendo assim, um aproveitamento oportuno de tempo e espaço.

\section{Metodologia da pesquisa}

A presente pesquisa utilizou como método a pesquisa de campo, documental e bibliográfica. Na pesquisa de campo, foram realizadas entrevistas com usuários e profissionais da UBS (Bauru/SP), além disso, foi realizada uma pesquisa de caráter descritivo-exploratório que buscou observar o processo comunicacional e, em quais aspectos podem ser propostas ações que garantam melhorias que perpetuem a integração entre as UBS, o Serviço Social, a Secretária da Saúde e a população usuária.

Já na pesquisa bibliográfica e documental, foi realizado um levantamento em bases de dados eletrônicas, sites acadêmicos e governamentais.

A pesquisa procurou desenvolver analise baseada no levantamento de estratégias de comunicação em massa no âmbito nacional com o interesse de atrelar tais situações no contexto da UBS; apresentar as necessidades e o conhecimento da população usuária das campanhas desenvolvidas; e, captar as necessidades dos profissionais que atuam no contexto pesquisado e quais os serviços que podem ser oferecidos ou implementados na unidade. 


\section{Resultados e discussão}

\section{Usuários e a Saúde}

A pesquisa com os usuários buscou apresentar a visão dos mesmos sobreaspectos relacionados à saúde, prevenção e qualidade no atendimento. O gráfico 1, apresenta que $100 \%$ dos entrevistados possuem conhecimento sobre o programa de promoção em saúde, no qual se visa promover a prevenção e conhecimento sobre as rotinas, direitos e deveres.

Gráfico 1: Conhecimento da Promoção em Saúde - Usuários

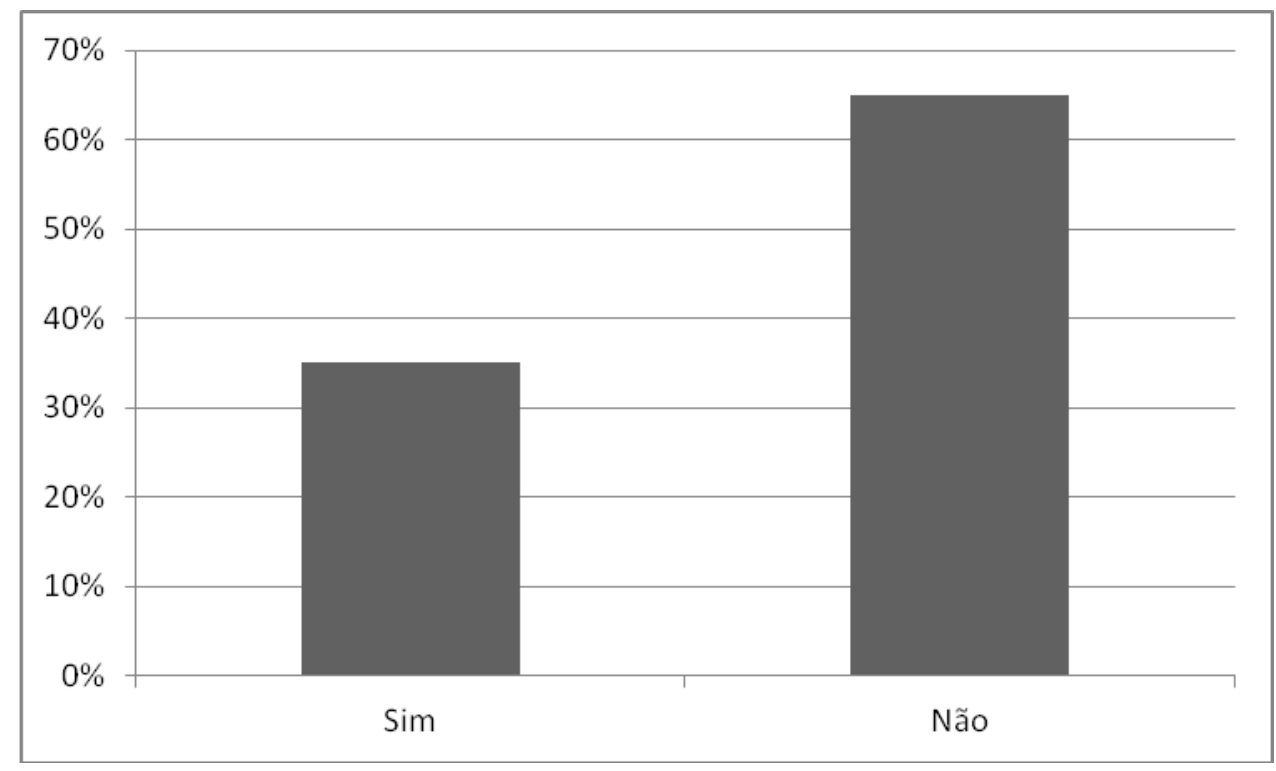

Fonte: Autores - Elaboração própria

O gráfico 2 apresenta que $100 \%$ dos entrevistados aderem ao sistema de prevenção de saúde como forma de melhorar sua qualidade de vida. 
Gráfico 2: Faz prevenção em Saúde - Usuários

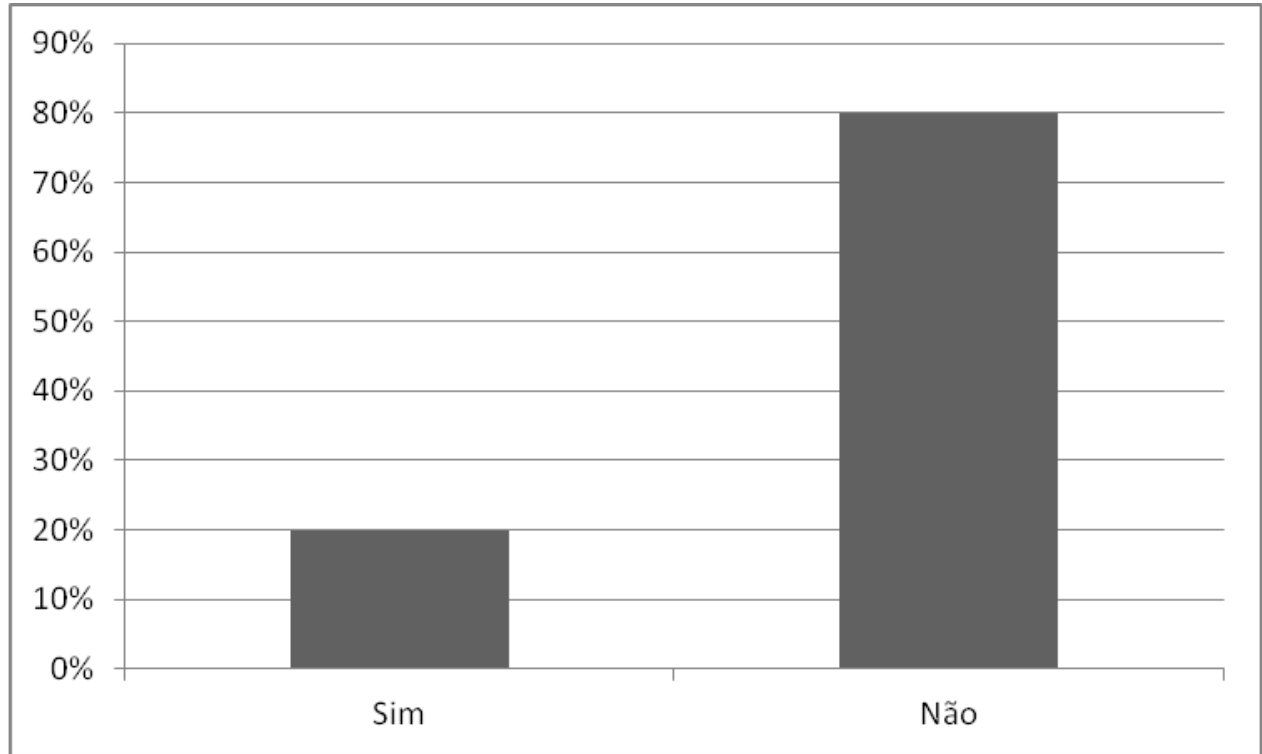

Fonte: Autores - Elaboração própria

No gráfico 3, seguindo os passos da comunicação dirigida e a necessidade de uma abordagem mais direta, os usuários aprovam o uso da sala de espera, tempo e espaço para promover palestras de prevenção em saúde, enquanto aguardam serem atendidos.

Gráfico 3: Índice de aprovação do uso da sala de espera pelos usuários

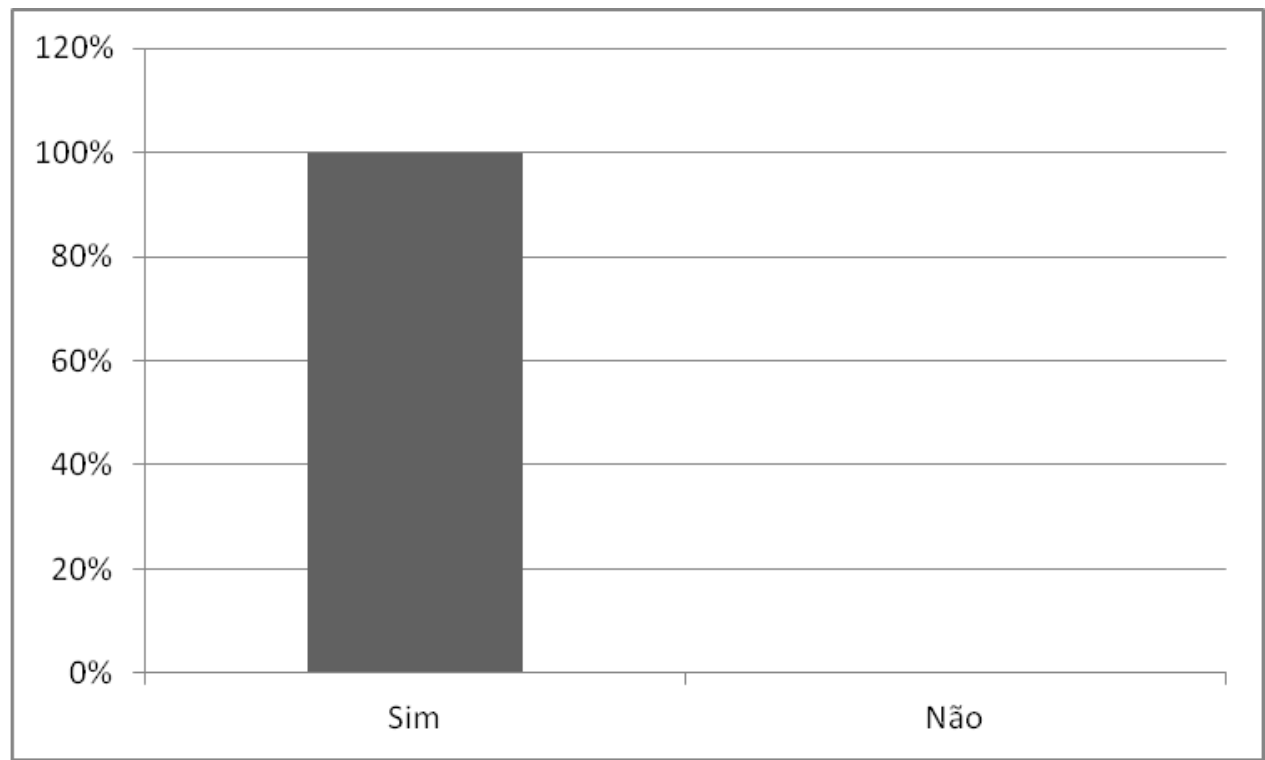

Fonte: Autores - Elaboração própria 
No gráfico 4, apresentação a satisfação dos usuários referente ao atendimento recebido pela UBS.

Gráfico 4: Qualidade no atendimento - Usuários

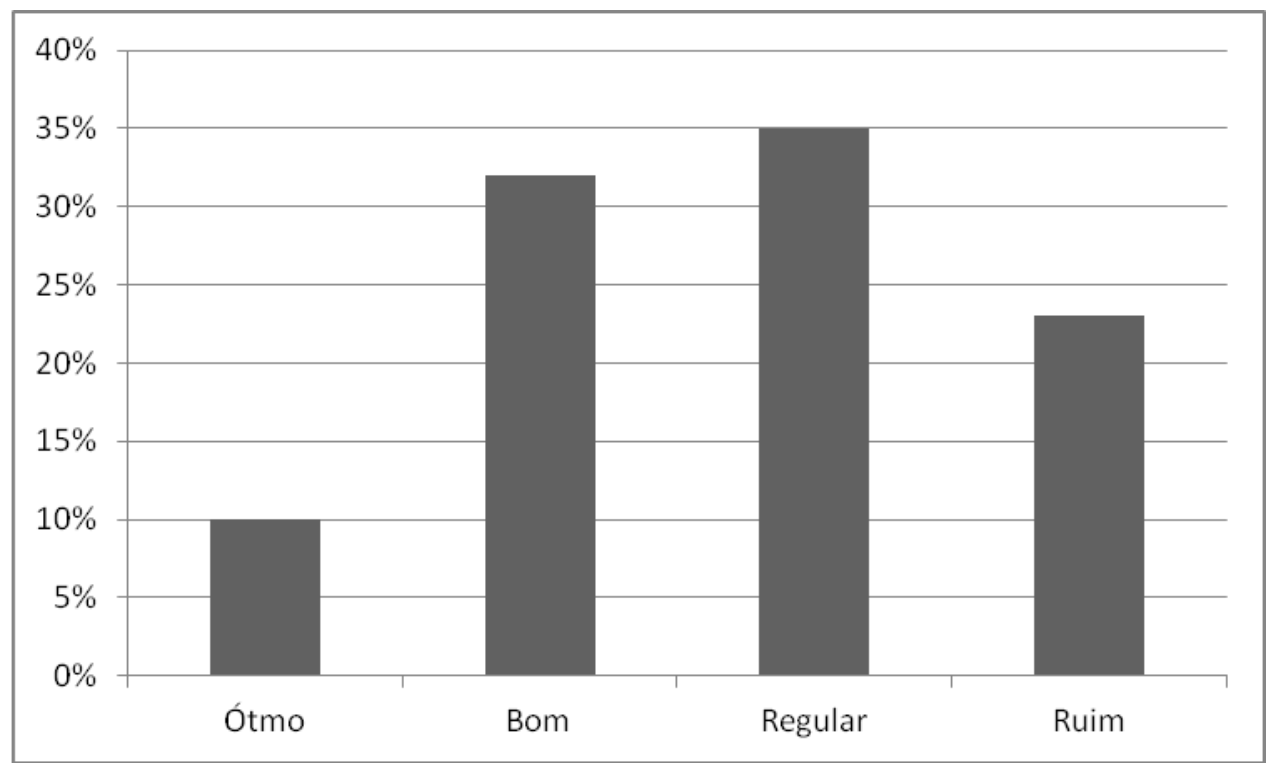

Fonte: Autores - Elaboração própria

Esta parte da pesquisa demonstrou que os usuários estão atentos aos seus direitos e, mostram que o atendimento pode ser melhorado. Também, que buscam ações de prevenção e contam com a Unidade Básica de Saúde para isso. Esses resultados apontam para a latente necessidade de comunicação dirigida cada vez mais integrada no cotidiano no Serviço Social e de Saúde.

\section{Profissionais da Saúde e Serviço Social}

A segunda etapa da pesquisa busca conhecer a visão dos profissionais em saúde que atuam em tarefas em que a comunicação é, em nossa visão, mais relevante (campanhas de prevenção, no atendimento e suporte aos usuários). O gráfico 5 apresenta a aprovação dos profissionais na utilização da sala de espera para promover palestras e ações em saúde. 
Gráfico 5: Índice de aprovação do uso da sala de espera pelos profissionais

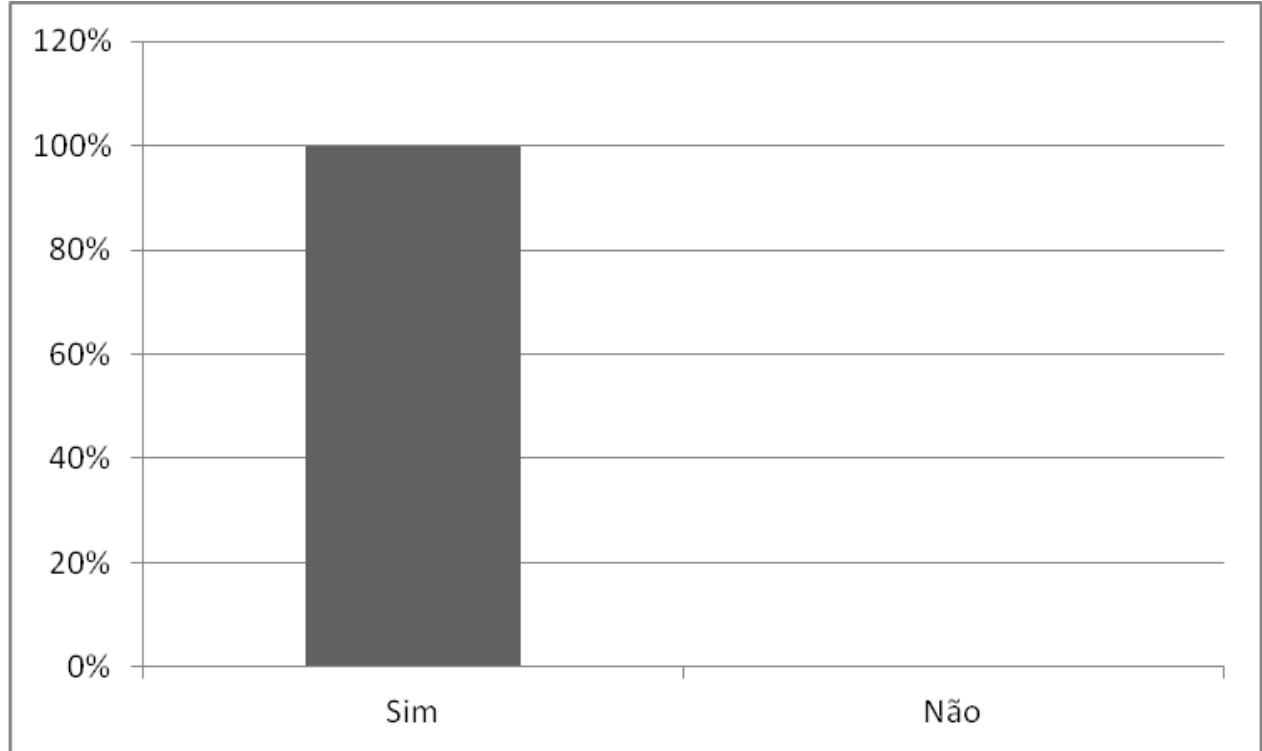

Fonte: Autores - Elaboração própria

Já o gráfico 6 aponta a avaliação dos profissionais a respeito da melhoria da comunicação nos serviços em saúde. Ao entrevistarmos os profissionais, o resultado é de que se necessita de melhores estratégias e ferramentas de comunicação. No questionário, esta pergunta foi aberta pois buscou captar suas necessidades e opiniões.

Gráfico 6: Precisa Melhorar a Comunicação - Profissionais

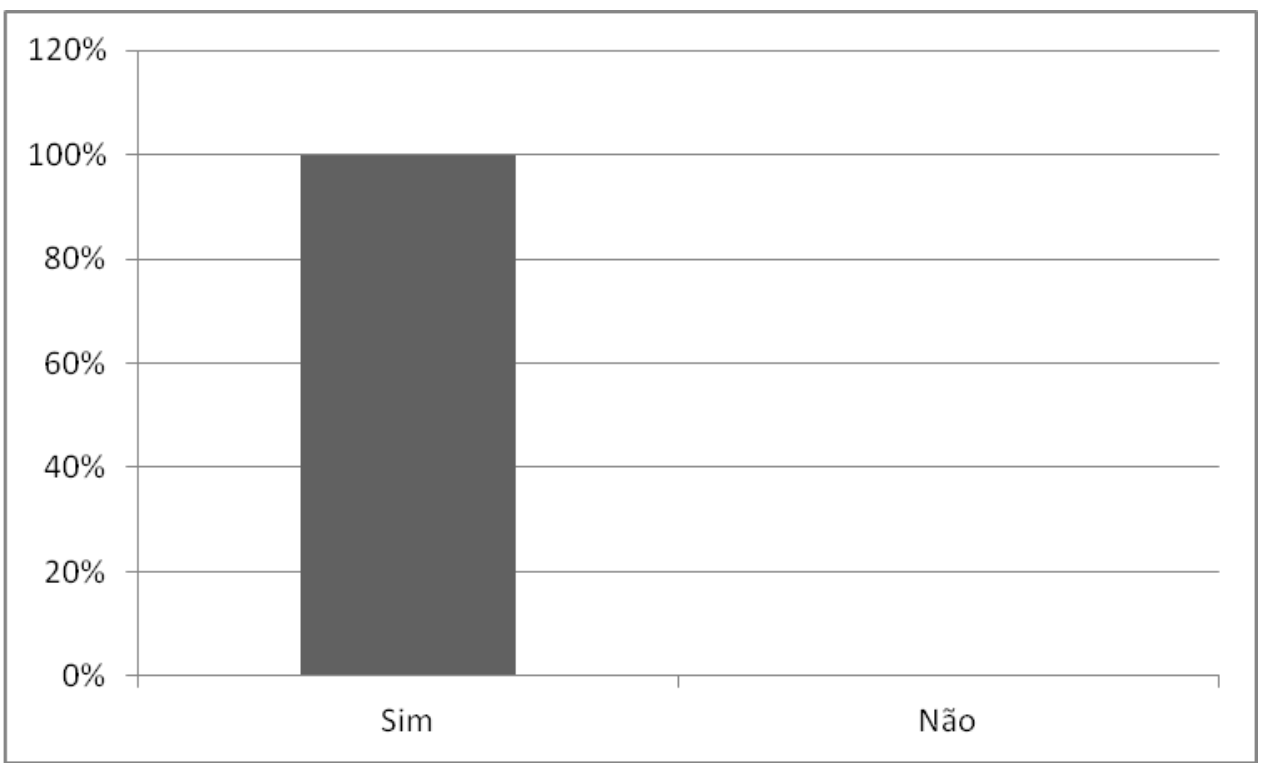

Fonte: Autores - Elaboração própria

As questões que apontam para a melhoria da comunicação são os que envolvem a necessidade de uma comunicação dirigida entre as UBS's (A pesquisada e as com 
demais unidades) e a Secretaria Municipal de Saúde. Foram apontadas as seguintes demandas: organizar a distribuição de cartazes para evitar a poluição visual; melhorar a interação dos serviços oferecidos; oferecer treinamento e capacitação da equipe; informatização e sistematização da assistência de saúde; melhorar o material visual; falta de material de divulgação; estrutura de informação em rede; informatizar as UBS e atendimento mais humanizado.

O gráfico 7 aponta aspectos de comunicação comunitária para melhor atender os usuários, buscando saber o que pode ser melhorado e como executar a melhoria.

Gráfico 7: Melhorar aspectos comunicação - Profissionais

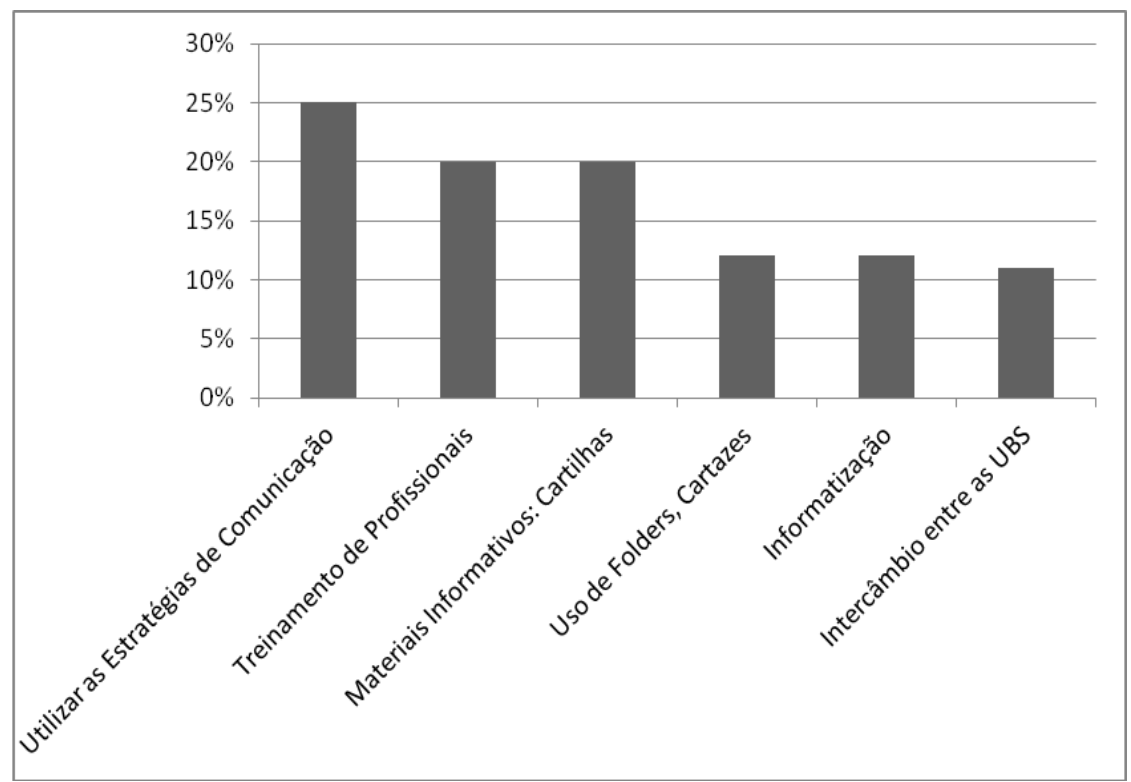

Fonte: Autores - Elaboração própria

Nesta etapa da pesquisa, utilizamos a pergunta: "O que falta em aspectos de comunicação comunitária para atender a população?”, e, ao analisar as respostas abertas notamos: falta de material de comunicação para saúde preventiva como folders e cartazes; falta de uso do tempo de espera pelos usuários nas recepções das UBS; falta de otimização do tempo para palestras e orientações aos usuários para ações preventivas; falta de informações aos usuários para a utilização das UBS; falta de vínculo entre as UBS e a população usuária, ficando a maior parte do serviço público flutuante; falta de integração entre as UBS.

Uma boa estratégia de comunicação é indispensável para a qualidade do atendimento aos usuários. Daí a necessidade de elaborar pontos estratégicos para a 
comunicação visual, para a integração entre as UBS que envolvam a Secretaria da Saúde com vista à melhor atender a população.

\section{Considerações finais}

Partindo do pressuposto de que é possível construir um objeto, portanto uma teorização da intervenção profissional e que, a partir dos conhecimentos no serviço social, é relevante a sua colocação na prática. A produção de conhecimentos se dá a partir de análises, observações e pesquisas que levem em consideração as necessidades reais dentro do contexto da saúde.

Avaliou-se a necessidade da comunicação e o papel do assistente social. Pudemos delinear a importância das comunicações na saúde, bem como, a importância desse profissional na promoção das ações de prevenção e informação.

Ao analisar os resultados da pesquisa, também pudemos verificar as deficiências no que se refere a material e estratégias de comunicação. Isso foi evidenciado pela escassez de materiais, a uso limitado da sala de espera para palestras e orientações, o desconhecimento dos usuários para a utilização correta das UBS, a falta de integração entre as UBS e entre as UBS e a Secretaria Municipal de Saúde, entre outros problemas já destacados. Assim, destacamos a necessidade de ações estratégicas na área da comunicação que informem a população usuária sobre os programas e campanhas em andamento, além de integrá-los as ações de saúde preventiva.

Essa pesquisa também mostrou a importância da comunicação integrada entre a população e as instituições envolvidas, e a importância do Serviço Social na comunicação em saúde, o que acaba por mostrar a relevância da comunicação interna perante todos os envolvidos. E, como a comunicação dirigida aos públicos favorece a prevenção e a disseminação do conhecimento e práticas. No entanto, faz-se necessário a criação de folders, cartazes e um jornal interno para a distribuição nas UBS para a população e seus profissionais Como uma maneira de alcançar as metas de informação significativas.

Como conclusão, esse trabalho mostra a relevância da comunicação na atuação do Serviço Social em Saúde para garantir a qualidade de atendimento e para a promoção de campanhas preventivas. Logo, a população se beneficia quando o conjunto de 
profissionais consegue promover ações em conjunto sendo a comunicação a base para isso acontecer efetivamente.

\section{REFERENCIAS}

AMADOR, Josy Ramos Oliveira. A prática do assistente social na atualidade: a sala de espera como alternativa nos espaços do plantão. Disponível em: <http://www.polemica.uerj.br/8(3)/artigos/contemp_5.pdf>. Acesso em: 20 jan. 2016.

ANDRADE, Cândido Teobaldo de Souza. Para entender relações públicas. 2. ed. São Paulo: Biblos, 1965.

BUSS, Paulo M. O conceito de promoção da saúde e os determinantes sociais. Disponível em: <http://www.ecodebate.com.br/2010/02/12/o-conceito-de-promocao-dasaude-e-os-determinantes-sociais-artigo-de-paulo-m-buss/>. Acesso em: 18 jan. 2016.

SANTOS CRUZ, José Anderson. A Comunicação e as relações públicas: o gerenciamento de crises. Disponível em: <http://fib.brpwebprojects.com/jornada/download/trabalhos/anais/0032011pp1.pdf $>$. Acesso em: 05 fev. 2016.

SANTOS CRUZ, José Anderson. A relação figura e efeito de sentido: discurso e retrato do embelezamento pessoal e a moda. Disponível em:

<http://fib.brpwebprojects.com/jornada/download/trabalhos/anais/0102011pp.pdf>. Acesso em: 05 fev. 2016.

FERREIRA, Waldir. A moda agora é comunicação dirigida. Disponível em: $<$ http://www.portal-

rp.com.br/bibliotecavirtual/relacoespublicas/comunicacaodirigida/0030.htm>. Acesso em: 30 jan. 2016.

HOHLFELDT, Antônio.; MARTINO, Luiz C.; FRANÇA, Vera Veiga. Teorias da Comunicação. $7^{\mathrm{a}}$ ed. Petrópolis, RJ: Vozes, 2007.

JORNAL Movimento Popular. A educação em saúde, a comunicação em saúde e a mobilização social na vigilância e monitoramento da qualidade da água para consumo humano. Disponível em:

<http://portal.saude.gov.br/portal/arquivos/pdf/artigo2.pdf>. Acesso em: 20 jan. 2016.

JVILSEMAR. Saúde e cidadania. Disponível em:

<http://vincit3.wordpress.com/2007/12/19/saude-e-cidadania/>. Acesso em: 25 jan. 2016.

KUNSH, Margarida Maria Krohling (org.). Obtendo resultados com Relações Públicas. São Paulo: Pioneira, 1997.

KUNSH, Margarida Krohlin. Planejamento de relações públicas na comunicação integrada. São Paulo. $4^{\text {a }}$ ed. Summus Editorial. 2003. 
LAKATOS, Eva Maria.; MARCONI, Marina de Andrade. Fundamentos da metodologia científica. $7^{\mathrm{a}}$ ed. São Paulo, Ed. Atlas, 2010.

MONTORO, Tânia. Retratos da comunicação em saúde: desafios e perspectivas. Disponível em: <http://www.scielo.br/scielo.php?script=sci_arttext\&pid=S141432832008000200020>. Acesso em: 27 dez. 2015.

PESTANA, Aretha Bley. Cultura como prática de cidadania: uma perspectiva ampliada do conceito. Disponível em:

<http://www.uel.br/revistas/uel/index.php/ssrevista/article/view/7779/9109>. Acesso em: 30 jan. 2016.

PNPS. Política Nacional de Prevenção à Saúde. Disponível em:

<http://portal.saude.gov.br/portal/arquivos/pdf/PNPS2.pdf >. Acesso em: 20 jan. 2016.

PORTAL da Saúde. Disponível em:

<http://portal.saude.gov.br/portal/saude/area.cfm?id_area=1794>. Acesso em: $20 \mathrm{dez}$. 2016.

RODRIGUES, Andrea Dornelles et al. Sala de espera: um ambiente para efetivar a educação em saúde. Disponível em:

$<$ http://www.reitoria.uri.br/ vivencias/Numero_007/artigos/artigos_vivencias_07/Artig o_13.pdf >. Acesso em: 20 dez. 2016.

SALES, Mione Apolinário.; RUIZ, Jefeferson Lee de Souza. Mídia, questão social e serviço social. $2^{\mathrm{a}}$ ed. São Paulo. Cortez Editora. 2009.

SUAS. Disponível em: <http://www.mds.gov.br/assistenciasocial/suas〉. Acesso em: 10 Ago 2011.

SUS. Campanhas temáticas. Disponível em:

<http://bvsms.saude.gov.br/bvs/sus/campanha_data.php>. Acesso em: 20 nov. 2015.

TEIXEIRA, José A. Carvalho. Comunicação em saúde. Disponível em:

<http://www.scielo.oces.mctes.pt/pdf/aps/v22n3/v22n3a21.pdf >. Acesso em: 20 jan. 2016.

VASCONCELOS, Ana Maria. A prática do Serviço Social: cotidiano, formação e alternativas na área de saúde. $7^{\mathrm{a}}$ ed. Cortez editora. São Paulo. 2011.

WOLF, Mauro. Teorias das comunicações de massa. $4^{a}$ ed. São Paulo. Editora WMF, 2009.

AGRADECIMENTOS: CAPES - Coordenação de Aperfeiçoamento de Pessoal de Nível Superior 


\section{Como referenciar este artigo}

SANTOS CRUZ, José Anderson.; BERMEJO, Lucas Justiniano.; KIZZY CUNHA, Arielly. Comunicação e mídia: uma questão social no serviço da saúde. Temas em Educ. e Saúde, Araraquara, v.13, n.1, p. 124-146, jan./jun. 2017. DOI <https://doi.org/10.26673/rtes.v13.n1.jan-jun2017.9.10541>. ISSN: 1517-7947.

Submetido em: 09/05/2017

Aprovado em: 20/08/2017 